\title{
Dementia is associated with poorer quality of care and outcomes after stroke: An Observational Study
}

Michele L. Callisaya, $\mathrm{PhD}^{1,2,3}$, Tara Purvis, $\mathrm{PhD}^{3}$, Katherine Lawler, $\mathrm{PhD}^{4}$, Amy Brodtmann ${ }^{5}$, PhD, Dominique A. Cadilhac, $\mathrm{PhD}^{3,5}$, Monique F. Kilkenny, $\mathrm{PhD}^{3,5}$

${ }^{1}$ Peninsula Clinical School, Central Clinical School, Monash University, Melbourne, Victoria, Australia

${ }^{2}$ Menzies Institute for Medical Research, University of Tasmania, Tasmania, Australia

${ }^{3}$ Stroke and Ageing Research, Department of Medicine, School of Clinical Sciences at Monash Health, Monash University, Clayton, Australia

${ }^{4}$ Wicking Dementia Research and Education Centre, College of Health and Medicine, University of Tasmania, Tasmania, Australia

${ }^{5}$ Stroke Division, Florey Institute of Neuroscience and Mental Health, Heidelberg, University of Melbourne, VIC, Australia

Corresponding Author: A/Prof Michele Callisaya, 2 Hasting Road, Frankston, Victoria, Australia; email: michele.callisaya@monash.edu

Statistical analyses were performed by Dr Tara Purvis

\section{Word count:}

Paper $=4078$

Abstract $=247$

Number of references $=36$

Number of tables $=4$

Supplementary tables: 4 


\begin{abstract}
BACKGROUND: To determine if pre-existing dementia is associated with poorer quality of care and outcomes after stroke in the acute hospital phase.
\end{abstract}

METHODS: This was a retrospective analysis of pooled data from the Australian Stroke Foundation national audit conducted in 2015 and 2017. Dementia status was obtained from the medical records. Processes of care to assess quality included: stroke unit care, time dependent therapy, nursing/allied health assessments and preparation for discharge. Outcomes included in-hospital complications, independence on discharge and destination. Logistic regression was used to examine associations between dementia status and processes of care. Multilevel random effects logistic regression, with level defined as hospital, was used to examine associations between dementia status and outcomes.

RESULTS: There were 683/7070 (9.7\%) audited patients with dementia included. Patients with dementia were less likely to be treated in stroke units (58.3\% versus $70.6 \%)$, receive thrombolysis if an ischemic stroke (5.8\% versus $11.1 \%$ ), have access within 48 hours to physiotherapy (56.4\% versus $69.7 \%$ ) or occupational therapy (46.8\% versus $55.6 \%)$, see a dietitian if problems with nutrition $(64.4 \%$ versus $75.9 \%)$, or have mood assessed $(2.6 \%$ versus $12.3 \%$ ). Patients with dementia were more likely to receive no rehabilitation (aOR $1.8895 \%$ CI $1.25,2.83)$ and be discharged to residential care (aOR $2.3695 \% \mathrm{CI} 1.50,3.72)$. CONCLUSION: People with dementia received poorer quality of care and had worse outcomes after stroke. Our findings raise questions regarding equity and the need for better understanding of why the quality of care differs after stroke for people with dementia.

Key words: stroke, dementia, acute, outcomes, observational 


\section{Introduction}

There are approximately 50 million people living with dementia worldwide, with numbers expected to rise to over 152 million by 2050 (1). Symptoms include impairments in cognition, behaviour, physical and psychological functioning leading to inability to perform activities of daily living or participate in social or life roles. Approximately $10 \%$ of patients with stroke have a pre-existing diagnosis of dementia $(2,3)$. With the growing numbers of people with both conditions, the challenge of managing and caring for this population will increase.

Similar to many other countries, Australia has clinical stroke guidelines that provide the recommendations for best-practice care and cover timely access to medical and rehabilitation treatments (4). Australian guidelines state that all patients admitted to hospital with stroke should receive stroke unit care (4) and be considered for rehabilitation with few exceptions (5). However, pre-existing impairments and life expectancy associated with dementia may increase the challenge of delivering recommended care, and lead to minimized treatments and referrals. In conditions such as hip fracture, patients with dementia are less likely to receive the same care as patients without dementia, despite their ability to improve (6).

Little is known about whether pre-existing dementia influences aspects of care or outcomes throughout the acute stroke hospital stay. Given the growing number of people with dementia, a greater understanding of the quality of care (i.e. management according to bestpractice guidelines) provided to this population may assist in highlighting any differences, and provide direction for future research and clinical practice improvements. The Stroke Foundation in Australia facilitates a national acute stroke audit of hospital care every two years, to measure adherence to the national clinical guideline recommendations (4). Therefore, the aim of this study was to compare the quality of care and outcomes of patients 
with and without pre-existing dementia, in the acute hospital phase after stroke, using data from the national stroke audit.

\section{Methods}

\section{Hospitals and participants}

Participation by hospitals in the national audit is voluntary. Staff at each hospital are trained in the use of the Australian Stroke Data Tool (7) which is the online database used to collect the audit data and includes information on patient characteristics, pre-stroke medical history (including pre-existing dementia), stroke type, clinical symptoms at time of admission, processes of care provided and outcomes (described further below). Hospital staff complete a retrospective audit of the medical records of 40 consecutive stroke cases from the year prior for their hospital (8). Data for these analyses were pooled from the 2015 (July to December 2014) and 2017 (July to December 2016) audits. For each audit cycle, up to five cases from hospitals are re-audited by a second staff member to determine the inter-rater reliability of the data abstraction.

The processes of care evaluated in this study were based on the Australian Stroke Clinical Guidelines (4). The specific processes include the following: Access to Stroke unit care (e.g. treated at any time in a stroke unit); Time-dependent therapy: (e.g. received intravenous thrombolysis if an ischemic stroke, brain scan within 24 hours); Nursing and Allied health management: (e.g. swallow screen prior to oral medications and food/fluid; assessed by allied health within 48 hours); Communication and preparation for discharge: evidence in the medical records of goals set with the patient and multidisciplinary team; patient and/or family received information on stroke (covering stroke, hospital management, secondary prevention and recovery); carer needs were assessed (emotional, physical, social, financial); a care plan 
was developed with patient and team; patient was discharged with secondary prevention medications.

The patient outcomes examined include the following: Complications during admission (e.g.: pneumonia; deep vein thrombosis; falls); Palliative care: documented management decision that the patient was not receiving curative treatments, only pain relieving and comfort measures; Death and level of independence at discharge (modified Rankin Scale [mRS] 0-2) (9); Length of stay and discharge destination (e.g. new residential care admission, in-patient rehabilitation). Further information on items in the audit can be found on the Australian Stroke Coalition website (10).

\section{Data analysis}

Patient characteristics (e.g. age, sex, and prior functional status), pre-stroke medical history, stroke type and deficits present at admission including inability to walk, arm weakness, speech impairment on admission and incontinence within 72 hours (indicative of stroke severity) were compared by dementia status. In the absence of the National Institutes of Health Stroke Scale, the deficits present at admission were used to indicate stroke severity (11). Logistic regression was used to examine associations between dementia and adherence to processes of care. Only valid responses were included for questions relating to impairments. 'Not documented' or 'unknown' responses were assumed negative and included in the denominator, or the denominators accounted for ineligible patients (e.g. processes only applicable for ischemic stroke were measured in those only with this type of stroke). No adjustment for confounders was undertaken as these processes were assumed to be important for all patients

Multilevel random effects logistic regression with level defined as hospital for binary outcomes or quantile regression with clustering for length of stay, were used to examine 
associations between dementia status and outcomes. A parsimonious approach to model building was used with clinically relevant confounders (age, sex, pre-admission mRS, stroke type, previous stroke and stroke severity indicators [inability to walk, arm weakness, speech impairment on admission and incontinence within 72 hours] (12)), and consideration of other variables with clinically meaningful differences observed in Table 1 (e.g. pre-stroke medical history). Standard techniques were implemented to determine included variables by checking for collinearity and model fit. For patients with dementia, outcomes were also compared by stroke unit status using the methods outlined above.

Three a priori sensitivity analyses were performed to assess differences in processes of care and outcomes by dementia status for varying profiles thought to influence findings: 1) excluding those from residential care; 2) excluding those where the primary aim was palliative management; 3 ) excluding those not treated in a stroke unit. One a posteriori analysis was undertaken to examine difference in outcomes by dementia status in those who were independent (mRS 0-2) prior to admission. All analyses were performed using STATA version 15.0. Ethics approval was obtained from Monash University Human Research Ethics committee (Project Number 8842). The Stroke Foundation approved access to the datasets for these analyses.

Data availability: On request from the Stroke Foundation (Australia).

\section{Results}

A total of 125 individual hospitals (91 with stroke units) participated in the 2015 and 2017 audits. After pooling the data, a total of 8279 records of patients who were hospitalized following a stroke were available for analysis. Of these, 7070 had dementia status documented ( $\mathrm{n}=1209$ missing), giving 693 patients with a history of dementia and 6377 without dementia. Those with dementia status missing were similar to those without dementia for most characteristics, except for pre-stroke medical history where the proportion of people 
with each condition was generally greater than in both the dementia and no dementia groups (Table 1 and eTable 1 in Supplement).

\section{Patient characteristics and demographics}

Table 1 shows the characteristics of patients by pre-stroke dementia status. Patients with dementia were less likely to be male, but a larger proportion were in the older age groups than patients without dementia. For example, $89.7 \%$ of those with dementia compared to $48.7 \%$ of those without dementia were aged $\geq 75$ years. Those with dementia were more likely to have risk factors for stroke, but less likely to be independent (mRS of 0-2) or living at home prior to their stroke. On admission, a smaller proportion of patients with dementia had an ischemic stroke, but were more likely to have arm weakness, speech impairments, incontinence within 72 hours of admission, and were more likely to be unable to walk compared with patients without dementia.

\section{Processes of care}

Patients with dementia were less likely to be treated in a stroke unit or receive intravenous thrombolysis if they had an ischemic stroke, but were more likely to be thrombolysed within 60 minutes compared with patients without dementia (Table 2).

\section{Nursing and allied health}

Patients with dementia were more likely to receive a swallow screen assessment before oral intake compared with patients without dementia. Patients with dementia were less likely to receive physiotherapy or occupational therapy within 48 hours of arrival to the hospital, see a dietitian if there were nutrition or hydration problems, or to be assessed for low mood compared with patients without dementia (Table 2).

Communication and preparation for discharge 
Patients with dementia and/or their family were more likely to meet with the team to discuss management, but they were less likely to have goals set or receive information about stroke. Documented reasons for not having goals set included: dementia (patient declined rehabilitation $2.4 \%$; returned to pre-morbid level of function $16.4 \%$; patient in a coma $12.1 \%$; treatment was futile 50.8\%; unknown 18.3\%) versus no dementia: (patient declined rehabilitation $3.3 \%$; returned to pre-morbid level of function $43.4 \%$; patient in a coma $7.6 \%$; treatment was futile 18.0\%; unknown 27.7\%) Carers of people with dementia were less likely to receive training. Reasons for not receiving training were documented as: dementia (patient transferred to another ward 30\%; carer declined 3.5\%; other 66.5\%) and no dementia (patient transferred to another ward 47\%; carer declined 3.8\%; other 49.2\%).

Fewer patients with dementia received education regarding secondary prevention prior to discharge, or were discharged on lipids, antihypertensive and antithrombotic medications. The main reason for not prescribing these medications (excluding those who refused or had contraindications) was the decision that treatment was futile (percentage documented as futile: lipid-lowering therapy - dementia $45.5 \%$; no dementia $40.3 \%$; antihypertensives dementia $67.7 \%$; no dementia $33.1 \%$ and antithrombotics - dementia $84 \%$; no dementia $63.4 \%)$.

\section{Outcomes}

There were no associations between dementia status and the majority of complications during the acute hospital stay (Table 3), except that dementia status was associated with a lesser likelihood of experiencing a new stroke in hospital. However, this result should be viewed with caution as the numbers were small (dementia $n=19$; no dementia $n=140$ ) and the unadjusted proportions showed a slightly greater percentage of people with dementia experiencing a new stroke $(2.7 \%$ vs $2.2 \%)$. Functional independence prior to stroke (mRS 0- 
2) was the variable that resulted in the largest change in the odds ratio when added to the model.

Dementia status was associated with lower odds of receiving rehabilitation. Reasons for not receiving rehabilitation included: dementia: (returned to premorbid level 24.3\%; palliation $39.0 \%$; coma/unresponsive $7.6 \%$; declined $5.4 \%$; plateaued $4.2 \%$; rehab goals met $1.4 \%$; other $18.1 \%$ ) and no dementia: (returned to premorbid level 57.5\%; palliation $15.1 \%$; coma/unresponsive 5.1\%; declined 4.6\%; plateaued 1.0\%; rehab goals met 1.6\%; other 15.0\%). Dementia status was also associated with greater odds of being made palliative or being admitted to residential care.

For patients with dementia only, treatment in a stroke unit was associated with less likelihood of stroke progression, palliative care or death, and a greater likelihood of receiving inpatient or any type of rehabilitation (Table 4). Stroke unit treatment was associated with greater odds of a symptomatic hemorrhagic transformation, but numbers were small (stroke unit $n=19$; no stroke unit $n=4)$.

\section{Sensitivity analyses}

Results from the three $a$ priori sensitivity analyses are presented in eTable 2 and eTable 3 in the Supplement. Findings altered for only a few processes of care quality indicators. If patients from residential care were excluded, there were no longer differences in the proportion of patients having their swallow or mood assessed or who were seen by a dietitian. There were also no longer differences in the odds of receiving any rehabilitation. However, for patients with dementia there was a longer length of stay and greater odds of falling, fever and stroke progression. If patients who were primarily for palliative care were excluded, there was also no longer differences in the proportion assessed for mood or if the team meet with the patient/family. If patients were treated in a stroke unit there was no longer differences in 
the proportion seen by an occupational therapist within 24 hours, whether the team met with the patient/family, or in receiving rehabilitation.

In a posteriori analysis (eTable 4) of outcomes limited to patients who were independent prior to their stroke (mRS 0-2), there were new associations between dementia status and aspiration pneumonia, falls and a longer length of stay. There were no longer associations between dementia status and a new stroke in hospital, palliative care or access to rehabilitation. Due to the small numbers (dementia $n=188$, no dementia $n=5,506$ ) these results should be interpreted with caution.

\section{Discussion}

The main findings of this study were that fewer patients with a history of dementia were provided with evidence-based care as described in the national clinical guidelines for stroke, and their outcomes in hospital were worse than patients without dementia. Fewer patients with dementia were treated in a stroke unit or received intravenous thrombolysis for an ischemic stroke. With the exception of social work and speech therapy, they were less likely to receive recommended allied health input, have goals set, receive secondary prevention management and their carers were less likely to receive training. For outcomes, patients with dementia were less likely to be referred for rehabilitation and were more likely to be admitted to residential care as a new resident. Importantly, if treated in a stroke unit, patients with dementia were more likely to receive rehabilitation and survive. It is rare to have such a comprehensive assessment of quality of care and outcomes in patients with acute stroke with and without dementia. These findings raise ethical and equity issues around decisions on the acute care provided to stroke patients with pre-existing dementia.

The minimum criteria for stroke units in Australia are co-located beds in a unit, a dedicated inter-professional team who have expertise in stroke and who meet at least once per week to discuss patient care, and have regular education and training (13). Treatment in a stroke unit 
was less likely to occur in patients with dementia. However, importantly we show that stroke unit care in this group was associated with lower likelihood of stroke progression and death. The reasons for fewer patients with dementia being treated in a stroke unit are unclear, as this finding persisted even after excluding those for palliative care management, but may relate to demand for acute stroke unit hospital beds. Poorer care when admitted to non-stroke unit beds may result from increased travel time for stroke teams, or less expert levels of stroke care on non-stroke wards (14). Australian stroke clinical guidelines recommend that all patients should be admitted to a stroke unit (4), irrespective of age, type or severity of stroke. For patients with suspected stroke presenting to a non-stroke unit hospitals, transfer protocols should be developed and used to guide urgent transfers to the nearest stroke unit. Treatment in such a unit is associated with greater access to evidence-based care (15) and reduced mortality and disability (14). Our findings suggest patients with dementia should be added to this list in the guideline.

A smaller proportion of patients with ischemic stroke and pre-existing dementia received thrombolysis (16). Although intravenous thrombolysis in patients with dementia is not specifically recommended against in guidelines (4), they are often excluded from clinical trials from which this evidence is drawn (2). There are concerns regarding increased risk of cerebral hemorrhage and mortality (17), and evidence that pre-existing low functional levels in patients with dementia is a reason for exclusion $(18,19)$. Alternatively, dementia may impair communication, making it difficult for clinicians to determine the time of stroke onset, complete a reliable examination, or obtain consent for treatment if family are unable to act as advocates (2). A surprising finding was that those with dementia were more likely to receive thrombolysis within 60 minutes. However, this result needs to be viewed with caution as this only occurred in 13 people with dementia. 
There were important differences in nursing and allied health processes of care, spanning physiotherapy, occupational therapy, dietetics, assessment of mood and training of carers. Both physiotherapy and occupational therapy assessments were less likely to occur within 48 hours if a person had a diagnosis of dementia, even when excluding those primarily for palliative care. It is recommended in the national guidelines that all patients with stroke should commence out of bed mobilization within 48 hours of stroke onset unless receiving end-of-life care or have other contraindications (4). However, the efficacy and safety of very early mobilisation within 24 hours of stroke onset (AVERT) trial, on which these recommendations are largely based (20), excluded those with $\mathrm{mRS}>2$ which would have excluded nearly a third of patients with dementia in this study. Our findings suggest there is a need for better evidence in this group of patients particularly around early mobilization. Poorer access to allied health may have partly been due stroke unit access (21), as differences in occupational therapy attenuated slightly when only including those treated in a stroke unit. It will be necessary in the future to explore if negative attitudes of allied health staff towards people with dementia (22) are associated with allocation of resources, and if better education regarding strategies and skills specific to engaging patients with dementia, improve quality of care and outcomes for this population.

Patients with and without dementia had similar levels of complications when taking into account confounders such as age and severity of stroke. An interesting finding was if only those who were independent prior to stroke were included, or if those originally from residential care were excluded, dementia was associated with greater odds of having a fall. It is well-recognized that cognitive impairment is an important risk factor for falls (23). However, delirium is not included in the audit, despite being common after stroke (24) and dementia (25), and may have contributed to falls in this group. 
Referral to rehabilitation was less in patients with dementia, even after excluding those on a palliative pathway (for pain and comfort care). Association attenuated when only including those independent prior to stroke or excluding those originally residing in residential care, despite guidelines recommending access should not differ based on prior living location or diagnosis $(5,26,27)$. We extend knowledge from existing literature (28) by highlighting that if patients with dementia were treated in a stroke unit, they were more likely to be referred to rehabilitation. Both service (allied health assessment, service pressures) (29-31) and patient factors (living in the community and pre- and post-stroke function and social supports) (2830) have previously been associated with referral to rehabilitation. Other contributing factors might include misconceptions about the ability of people with dementia to engage and their capability to improve $(30,32)$. After hip fracture, patients with dementia are less likely to receive rehabilitation (33), but those with at least mild-moderate dementia were able to improve given more time $(6,34)$, reinforcing that dementia should not be considered as one disease in terms of severity. Shared care or specialist ortho-geriatricians have been important in the improvement of outcomes after hip fracture (35) and along with further education for staff could be investigated in relation to outcomes after stroke.

The strengths of our study include pooled data from a large standardized national dataset, with a comprehensive range of 'real world' processes of care quality indicators for stroke, obtained from a wide range of Australian hospitals with and without a stroke unit. The audit only includes 40 patients from each hospital for each year of the audit, but there is no reason to believe these are not representative of all stroke admissions. We pooled the data from two audit periods and therefore cannot be certain that patients were not readmissions for recurrent stroke. Audits are only as good as the information recorded in the medical records and International Classification of Disease codes for dementia were not obtained at the time of audit. There was also a reasonably large amount of missing data for documentation of 
dementia. Those that had missing documented dementia status were similar in age, pre-stroke living condition and independence to those without dementia, but there was a greater proportion with pre-existing medical problems than in both groups. Therefore, we cannot rule out missing cases where dementia had not been diagnosed. However, the proportion of $10 \%$ with dementia is similar to that of prior studies $(3,16)$. There was no information on dementia type or severity (e.g. the Clinical Dementia Scale for dementia) or the National Institute of Health Stroke Scale for stroke, which may have influenced some aspects of care. We attempted to address this by using prior living condition and palliative care status in sensitivity analyses and adjusting for pre-admission mRS, although we acknowledge that there may have been residual confounding by other unmeasured factors. Delirium was not included in the audit questions, but it is common in people with dementia and may have influenced processes or care. We also did not have information on newer therapies such as endovascular clot retrieval. Data entry may have been influenced by responder bias. However, the web-based data entry tool has inbuilt logic checks and requires mandatory responses to questions, and a-prior inter-rater reliability analyses found substantial to near perfect agreement for most variables (36), including dementia (kappa $0.8595 \%$ CI 0.64,1.00). Finally, numbers were small for some outcomes and we were unable to determine for many indicators the reason for the differences in care, which should be the focus of future studies.

In summary, patients with dementia received poorer quality of care in a number of organizational, medical, allied health and outcome indicators after they experienced stroke. Our findings raise ethical questions around the quality and equity of care provided to patients with dementia. Further research in patients with dementia and stroke is needed to generate evidence for or against some aspects of stroke care, as well as studies investigating factors associated with better outcomes. This work is important given the growing number of people 
with dementia and stroke and the subsequent social and economic impacts anticipated for individuals and the community.

\section{Funding:}

The following authors receive Research Fellowship support from the National Health and Medical Research Council of Australia: M.L.C (\#1135761). M.F.K (\#1109426) and D.A.C (\#1154273). T.P and K.L have no disclosures. A.B. is on the editorial board of Neurology.

Conflicts of interest: There were no conflicts of interest.

Acknowledgements: We acknowledge the hospitals participating in the National Stroke Audit and the clinicians who contributed to data collection using the Australian Stroke Data Tool (AuSDaT). The National Stroke Audit is coordinated by the Stroke Foundation. The study was supported by the National Stroke Foundation.

Author contribution: MC: Design and conceptualization of the study, interpretation of the data, drafting and revising the manuscript for intellectual content; TP: Design and conceptualization of the study, analysis, interpretation of the data, drafting and revising the manuscript for intellectual content KL: Interpretation of the data, revising the manuscript for intellectual content. AB: Interpretation of the data, revising the manuscript for intellectual content. DC: Interpretation of the data, revising the manuscript for intellectual content. MK: Design and conceptualization of the study, interpretation of the data, revising the manuscript for intellectual content. 


\section{References}

1. World Health Organisation. Dementia fact sheet. World Health Organisation; 2019.

2. Subic A, Cermakova P, Norrving B, Winblad B, von Euler M, Kramberger MG, et al. Management of acute ischaemic stroke in patients with dementia. J Intern Med. 2017;281:348-364. https://doi.10.1111/joim.12588.

3. Pendlebury ST, Rothwell PM. Prevalence, incidence, and factors associated with prestroke and post-stroke dementia: a systematic review and meta-analysis. Lancet Neurol. 2009;8:1006-1018. https://doi.10.1016/S1474-4422(09)70236-4.

4. Stroke Foundation Australia. Clinical Guidelines for stroke management. Australia; 2017.

5. Australian Stroke Coalition Rehabilitation Working Group. Assessment for Rehabilitation: Pathway and Decision-Making Tool. Melbourne, Australia; 2012.

6. Allen J, Koziak A, Buddingh S, Liang J, Buckingham J, Beaupre LA. Rehabilitation in patients with dementia following hip fracture: a systematic review. Physiother Can. 2012;64:190-201. https://doi.10.3138/ptc.2011-06BH.

7. Stroke Foundation Australia. Acute Stroke Services Audit Australia: Stroke Foundation; 2015 and 2017.

8. Harris D, Cadilhac DA, Hankey GJ, Hillier SL, Kilkenny MF, Lalor E, et al. National Stroke Audit: The Australian Experience. Clinical Audit. 2010;2:25-31.

9. van Swieten JC, Koudstaal PJ, Visser MC, Schouten HJ, van Gijn J. Interobserver agreement for the assessment of handicap in stroke patients. Stroke. 1988;19:604-607. https://doi.10.1161/01.str.19.5.604.

10. Australian Stroke Coalition. Australian Stroke Data Tool. Australia; 2019. 
11. Sim J, Teece L, Dennis MS, Roffe C, Team SOSS. Validation and Recalibration of Two Multivariable Prognostic Models for Survival and Independence in Acute Stroke. PLoS One. 2016;11:e0153527. https://doi.10.1371/journal.pone.0153527.

12. Counsell C, Dennis M, McDowall M, Warlow C. Predicting outcome after acute and subacute stroke: development and validation of new prognostic models. Stroke. 2002;33:1041-1047. https://doi.10.1161/hs0402.105909.

13. National Stroke Foundation. Acute Stroke Services Framework 2019. Australia; 2019.

14. Stroke Unit Trialists C. Organised inpatient (stroke unit) care for stroke. Cochrane Database Syst Rev. 2013:CD000197. https://doi.10.1002/14651858.CD000197.pub3.

15. Cadilhac DA, Kilkenny MF, Lannin NA, Dewey HM, Levi CR, Hill K, et al. Outcomes for Patients With In-Hospital Stroke: A Multicenter Study From the Australian Stroke Clinical Registry (AuSCR). J Stroke Cerebrovasc Dis. 2019;28:1302-1310. https://doi.10.1016/j.jstrokecerebrovasdis.2019.01.026.

16. Saposnik G, Cote R, Rochon PA, Mamdani M, Liu Y, Raptis S, et al. Care and outcomes in patients with ischemic stroke with and without preexisting dementia. Neurology. 2011;77:1664-1673. https://doi.10.1212/WNL.0b013e31823648f1.

17. Busl KM, Nogueira RG, Yoo AJ, Hirsch JA, Schwamm LH, Rost NS. Prestroke dementia is associated with poor outcomes after reperfusion therapy among elderly stroke patients. J Stroke Cerebrovasc Dis. 2013;22:718-724. https://doi.10.1016/j.jstrokecerebrovasdis.2011.11.005.

18. Zupanic E, von Euler M, Kareholt I, Contreras Escamez B, Fastbom J, Norrving B, et al. Thrombolysis in acute ischemic stroke in patients with dementia: A Swedish registry study. Neurology. 2017;89:1860-1868. https://doi.10.1212/WNL.0000000000004598.

19. Craig L, Middleton S, Hamilton H, Cudlip F, Swatzell V, Alexandrov A, et al. Does the Addition of Non-Approved Inclusion and Exclusion Criteria for rtPA Impact Treatment 
Rates? Findings in Australia, the United Kingdom and the United States of America. Interventional Neurology 2019;8:1-12. https://doi.10.1159/000493020.

20. Avert Trial Collaboration group. Efficacy and safety of very early mobilisation within $24 \mathrm{~h}$ of stroke onset (AVERT): a randomised controlled trial. Lancet. 2015;386:46-55. https://doi.10.1016/S0140-6736(15)60690-0.

21. Cadilhac DA, Kilkenny MF, Andrew NE, Ritchie E, Hill K, Lalor E, et al. Hospitals admitting at least 100 patients with stroke a year should have a stroke unit: a case study from Australia. BMC health services research. 2017;17:212.

https://doi.10.1186/s12913-017-2150-2.

22. Goodwin V, Allan LM. 'Mrs Smith has no rehab potential': does rehabilitation have a role in the management of people with dementia? Age and Ageing. 2019;1:5-7.

23. Taylor ME, Delbaere K, Lord SR, Mikolaizak AS, Close JC. Physical impairments in cognitively impaired older people: implications for risk of falls. Int Psychogeriatr. 2013;25:148-156. https://doi.10.1017/S1041610212001184.

24. Alvarez-Perez FJ, Paiva F. Prevalence and Risk Factors for Delirium in Acute Stroke Patients. A Retrospective 5-Years Clinical Series. J Stroke Cerebrovasc Dis. 2017;26:567-573. https://doi.10.1016/j.jstrokecerebrovasdis.2016.11.120.

25. McManus J, Pathansali R, Stewart R, Macdonald A, Jackson S. Delirium post-stroke. Age Ageing. 2007;36:613-618. https://doi.10.1093/ageing/afm140.

26. Crocker T, Forster A, Young J, Brown L, Ozer S, Smith J, et al. Physical rehabilitation for older people in long-term care. Cochrane Database Syst Rev. 2013:CD004294. https://doi.10.1002/14651858.CD004294.pub3.

27. Pereira S, Graham JR, Shahabaz A, Salter K, Foley N, Meyer M, et al. Rehabilitation of individuals with severe stroke: synthesis of best evidence and challenges in 
implementation. Topics in stroke rehabilitation. 2012;19:122-131. https://doi.10.1310/tsr1902-122.

28. Lynch EA, Mackintosh S, Luker JA, Hillier SL. Access to rehabilitation for patients with stroke in Australia. Med J Aust. 2019;210:21-26. https://doi.10.5694/mja2.12034.

29. Labberton AS, Barra M, Ronning OM, Thommessen B, Churilov L, Cadilhac DA, et al. Patient and service factors associated with referral and admission to inpatient rehabilitation after the acute phase of stroke in Australia and Norway. BMC health services research. 2019;19:871. https://doi.10.1186/s12913-019-4713-x.

30. Longley V, Peters S, Swarbrick C, Bowen A. What factors affect clinical decisionmaking about access to stroke rehabilitation? A systematic review. Clin Rehabil. 2019;33:304-316. https://doi.10.1177/0269215518808000.

31. Longley V, Peters S, Swarbrick C, Bowen A. What influences decisions about ongoing stroke rehabilitation for patients with pre-existing dementia or cognitive impairment: a qualitative study? Clin Rehabil. 2018;32:1133-1144. https://doi.10.1177/0269215518766406.

32. Isbel ST, Jamieson MI. Views from health professionals on accessing rehabilitation for people with dementia following a hip fracture. Dementia (London). 2017;16:10201031. https://doi.10.1177/1471301216631141.

33. Mitchell R, Harvey L, Brodaty H, Draper B, Close J. Hip fracture and the influence of dementia on health outcomes and access to hospital-based rehabilitation for older individuals. Disabil Rehabil. 2016;38:2286-2295. https://doi.10.3109/09638288.2015.1123306.

34. Muir SW, Yohannes AM. The impact of cognitive impairment on rehabilitation outcomes in elderly patients admitted with a femoral neck fracture: a systematic review. J Geriatr Phys Ther. 2009;32:24-32. https://doi.10.1519/00139143-200932010-00006 
35. Zeltzer J, Mitchell RJ, Toson B, Harris IA, Ahmad L, Close J. Orthogeriatric services associated with lower 30-day mortality for older patients who undergo surgery for hip fracture. Med J Aust. 2014;201:409-411. https://doi.10.5694/mja14.00055.

36. Purvis T, Kilkenny MF, Middleton S, Cadilhac DA. Influence of stroke coordinators on delivery of acute stroke care and hospital outcomes: An observational study. Int J Stroke. 2018;13:585-591. https://doi.10.1177/1747493017741382. 
Table 1: Sample characteristics by dementia status

Table 2: Associations between dementia status and processes of care indicators

Table 3: Multivariable analyses of associations between dementia status and outcomes in hospital and at discharge

Table 4: Associations between stroke unit status and outcomes (patients with dementia only) 
Table 1: Sample characteristics by dementia status

\begin{tabular}{|c|c|c|c|c|}
\hline & \multicolumn{2}{|c|}{$\begin{array}{l}\text { Dementia } \\
\mathrm{N}=693\end{array}$} & \multicolumn{2}{|c|}{$\begin{array}{c}\text { No dementia } \\
\mathrm{N}=6377\end{array}$} \\
\hline & & $\mathrm{n} \%$ & & $\mathrm{n} \%$ \\
\hline \multicolumn{5}{|l|}{ Patient demographics } \\
\hline Age, median (Q1, Q3) & 85 & $(80,89)$ & 74 & $(64,83)^{*}$ \\
\hline \multicolumn{5}{|l|}{ Age group } \\
\hline$<65$ years & 9 & 1.3 & 1701 & 26.7 \\
\hline $65-74$ years & 63 & 9.0 & 1567 & 24.6 \\
\hline $75-84$ & 252 & 36.4 & 1858 & 29.2 \\
\hline $85+$ & 369 & 53.3 & 1244 & 19.5 \\
\hline Male & 296 & 42.7 & 3601 & 56.5 \\
\hline Aboriginal or Torres Strait Islander, & 6 & 0.9 & 165 & 2.6 \\
\hline Interpreter required, & 70 & 10.1 & 363 & 5.7 \\
\hline \multicolumn{5}{|l|}{ Living situation prior to stroke } \\
\hline Home (+/- others) & 371 & 53.5 & 6032 & 94.6 \\
\hline Supported accommodation & 319 & 46.0 & 299 & 4.7 \\
\hline Other & 3 & $<1$ & 46 & $<1$ \\
\hline Independence prior to stroke (mRS 0-2) & 188 & 27.1 & 5506 & $86.4^{*}$ \\
\hline \multicolumn{5}{|l|}{ Pre stroke history, } \\
\hline Atrial fibrillation & 256 & $42.4 \dagger$ & 1507 & $24.4^{\circ}$ \\
\hline Prior stroke & 252 & $40.7 \dagger$ & 1308 & $20.9^{\circ}$ \\
\hline Transient ischemic attack & 131 & $22.1 \dagger$ & 754 & $12.3^{\circ}$ \\
\hline Diabetes & 165 & $26.8 \dagger$ & 1530 & $24.4^{*}$ \\
\hline Hypercholesterolemia & 233 & $39.2 \dagger$ & 2480 & $40.4^{\circ}$ \\
\hline Hypertension & 477 & $73.5^{\sim}$ & 4180 & $66.4^{*}$ \\
\hline Ischemic heart disease & 192 & $32.1 \dagger$ & 1506 & $24.3^{\circ}$ \\
\hline Alcohol consumption & 34 & $6.8^{\ddagger}$ & 616 & $11.0 \dagger$ \\
\hline Now or ever smoker & 96 & 25.7 & 2141 & $41.5 \dagger$ \\
\hline \multicolumn{5}{|l|}{ Clinical information on admission } \\
\hline \multicolumn{5}{|l|}{ Stroke type, $n \%$} \\
\hline Hemorrhagic & 125 & 18.0 & 758 & 11.9 \\
\hline Ischemic & 489 & 70.6 & 5247 & 82.3 \\
\hline Undetermined/unknown & 79 & 11.4 & 372 & 5.8 \\
\hline \multicolumn{5}{|l|}{ Stroke severity indicators } \\
\hline Arm weakness ${ }^{\wedge}$ & 442 & $69.9^{\sim}$ & 3860 & $59.2^{\circ}$ \\
\hline Speech impairment $^{\wedge}$ & 459 & $71.8^{\sim}$ & 3476 & $56.0^{\circ}$ \\
\hline Incontinence in first $72 \mathrm{hrs}$ & 462 & $68.9^{\circ}$ & 1831 & $29.6^{\circ}$ \\
\hline Unable to walk^^ & 514 & $76.3^{\circ}$ & 3164 & $51.2^{\circ}$ \\
\hline
\end{tabular}

Q1: $1^{\text {st }}$ quartile, Q3: $3^{\text {rd }}$ quartile; mRS - modified Rankin Scale, ${ }^{\wedge}$ on admission; $*<1 \%$ missing/unknown data; ${ }^{\circ} 2-<5 \%$ missing/unknown data; $\sim 5-<10 \%$ missing/unknown data; $\dagger 10-<20 \%$ missing/unknown data; $\$<45 \%$ missing/unknown data; 
Table 2: Associations between dementia status and processes of care indicators

\begin{tabular}{lrrrrrr}
\hline & $\begin{array}{c}\text { Dementia } \\
\mathrm{N}=693 \\
\mathrm{n}(\%)\end{array}$ & $\begin{array}{c}\text { No dementia } \\
\mathrm{N}=6377 \\
\mathrm{n}(\%)\end{array}$ & \multicolumn{2}{c}{ OR 95\% CI } \\
\hline $\begin{array}{l}\text { Treated in a stroke unit at any time } \\
\text { Time dependent therapy }\end{array}$ & 404 & 58.3 & 4504 & 70.6 & $\mathbf{0 . 5 8}$ & $\mathbf{0 . 4 9 , 0 . 6 8}$ \\
Received thrombolysis if ischemic stroke & 24 & 5.8 & 504 & 11.1 & $\mathbf{0 . 5 0}$ & $\mathbf{0 . 3 3 , 0 . 7 6}$ \\
Received thrombolysis within 60 minutes & 13 & 54.2 & 140 & 27.8 & $\mathbf{3 . 0 7}$ & $\mathbf{1 . 3 4 , 7 . 0 7}$ \\
Brain scan within 24 hours of stroke & 613 & 90.7 & 5731 & 90.7 & 1.00 & $0.76,1.31$
\end{tabular}

Nursing and allied health

Swallow screen/assessment prior to oral intake

$\begin{array}{llll}404 & 58.3 & 3393 & 53.2\end{array}$

$1.23 \quad 1.05,1.44$

Assessed within 48 hours of ED arrival

Physiotherapist

$\begin{array}{llll}390 & 56.4 & 4432 & 69.7\end{array}$

$0.56 \quad 0.48,0.66$

Occupational therapist

Speech therapist

Social work assessment

$282 \quad 46.8$

$3352 \quad 55.6$

$\begin{array}{ll}0.70 & 0.59,0.83\end{array}$

$\begin{array}{llll}447 & 71.5 & 4050 & 69.4\end{array}$

$\begin{array}{ll}1.11 & 0.92,1.30\end{array}$

$315 \quad 57.5$

$\begin{array}{ll}2867 & 57.2\end{array}$

$\begin{array}{ll}1.01 & 0.84,1.21\end{array}$

Dietitian if nutrition or hydration problems

$\begin{array}{llll}114 & 64.4 & 588 & 75.9\end{array}$

$\begin{array}{ll}0.58 & 0.41,0.82\end{array}$

Mood assessed

Psychology assessment if mood impairment

$122 \quad 17.6$

$\begin{array}{ll}1508 & 23.7\end{array}$

$\begin{array}{ll}0.69 & 0.56,0.85\end{array}$

12.6

$\begin{array}{ll}46 & 12.3\end{array}$

$0.19 \quad 0.03,1.45$

Communication and preparation for

discharge

Team met with patient/family

Goals set

Received information on stroke

Risk factor advice prior to discharge

Care plan developed with team and patient

Discharge summary to primary care

physician

Carer needs assessed

$\begin{array}{llll}604 & 87.2 & 5325 & 83.5\end{array}$

$1.34 \quad 1.06,1.69$

$\begin{array}{ll}279 & 40.3\end{array}$

$\begin{array}{ll}4319 & 67.7\end{array}$

$\begin{array}{ll}0.32 & 0.27,0.40\end{array}$

$247 \quad 35.6$

$\begin{array}{ll}3776 & 59.2\end{array}$

$0.38 \quad 0.32,0.45$

$\begin{array}{llll}89 & 23.0 & 2242 & 65.4\end{array}$

$0.16 \quad 0.12,0.20$

$\begin{array}{llll}209 & 58.4 & 2092 & 62.5\end{array}$

$0.84 \quad 0.68,1.05$

$\begin{array}{lllllll}447 & 95.5 & 4686 & 94.7 & 1.19 & 0.76,1.88\end{array}$

Carer training provided

$\begin{array}{llll}95 & 57.2 & 357 & 55.9\end{array}$

$\begin{array}{ll}1.06 & 0.75,1.49\end{array}$

$\begin{array}{ll}61 & 36.8\end{array}$

$329 \quad 51.5$

$0.55 \quad 0.38,0.78$

Secondary prevention medications prescribed on discharge^

Antithrombotics

$\begin{array}{llll}235 & 82.8 & 2790 & 96.4\end{array}$

$0.18 \quad 0.12,0.26$

Antihypertensives

$\begin{array}{llll}235 & 62.2 & 2507 & 75.1\end{array}$

$\begin{array}{lll}0.54 & 0.44,0.68\end{array}$

Lipid lowering medication

$\begin{array}{llll}159 & 56.8 & 2430 & 84.5\end{array}$

$0.24 \quad 0.19,0.31$

OR: Odds ratio; CI; Confidence Interval; Bold font: p<0.05; ED: Emergency Department; ^ ${ }^{\wedge}$ if ischemic stroke for antithrombotics \& lipid lowering medications 


\begin{tabular}{|c|c|c|c|c|c|c|}
\hline Complications during admission & \multicolumn{2}{|c|}{$\begin{array}{c}\text { Dementia } \\
\mathrm{N}=693 \\
\mathrm{n}(\%)\end{array}$} & \multicolumn{2}{|c|}{$\begin{array}{c}\text { No dementia } \\
\mathrm{N}=6377 \\
\mathrm{n}(\%)\end{array}$} & Adjusted $\mathrm{OR}^{\circ}$ & $95 \% \mathrm{CI}$ \\
\hline Aspiration pneumonia & 94 & 13.6 & 358 & 5.6 & 1.21 & $0.86,1.71$ \\
\hline Deep vein thrombosis & 2 & 0.29 & 37 & 0.6 & 0.58 & $0.12,2.76$ \\
\hline Fall & 54 & 7.8 & 296 & 4.6 & 1.48 & $0.98,2.25$ \\
\hline Fever & 103 & 14.9 & 599 & 9.4 & 1.12 & $0.82,1.54$ \\
\hline Hemorrhagic transformation & 23 & 3.3 & 161 & 2.5 & 1.01 & $0.54,1.85$ \\
\hline Atrial fibrillation - new onset & 29 & 4.2 & 360 & 5.7 & 0.72 & $0.45,1.17$ \\
\hline New stroke & 19 & 2.7 & 140 & 2.2 & 0.48 & $0.24,0.96$ \\
\hline Stroke progression & 83 & 12.0 & 509 & 8.0 & 0.76 & $0.54,1.08$ \\
\hline Urinary tract infection & 73 & 10.5 & 338 & 5.3 & 0.86 & $0.60,1.23$ \\
\hline Seizure & 25 & 3.6 & 153 & 2.4 & 0.99 & $0.57,1.72$ \\
\hline \multicolumn{7}{|l|}{ Death and independence at discharge } \\
\hline Primary aim was palliative care & 152 & 21.9 & 319 & 5.0 & 1.62 & $1.16,2.27$ \\
\hline Died in hospital & 156 & 22.5 & 555 & 8.7 & 1.02 & $0.76,1.38$ \\
\hline Independent on discharge (mRS $0-2)^{*}$ & 53 & 9.9 & 3109 & $53.5^{\dagger}$ & 0.31 & $0.20,0.49$ \\
\hline \multicolumn{7}{|l|}{ Hospital and discharge outcomes } \\
\hline Discharged to residential care (new admission) & 56 & 10.4 & 140 & 2.4 & 2.36 & $1.50,3.72$ \\
\hline Discharged to inpatient rehabilitation & 101 & 18.8 & 1707 & 29.3 & 0.39 & $0.29,0.52$ \\
\hline \multirow[t]{2}{*}{ Received no ongoing rehabilitation^^${ }^{\wedge}$} & 337 & 87.1 & 2609 & 76.2 & 1.88 & $1.25,2.83$ \\
\hline & & & & & Co-efficient ${ }^{\circ}$ & $95 \% \mathrm{CI}$ \\
\hline Length of stay ${ }^{*}$ (median Q1, Q3) & 6 & $3,11^{\dagger}$ & 5 & $3,9 \dagger$ & -0.67 & $-1.41,0.73$ \\
\hline
\end{tabular}


Bold font: $\mathrm{p}<0.05$; *excluding deaths; ^ outpatient or community (dementia 337/387 and no dementia 2609/3426); $\dagger<1 \%$ missing data; CI- confidence interval; OR- odds ratio; mRS- modified rankin scale; ${ }^{\circ}$ adjusted for age, sex, independence prior to admission, stroke type and impairments on admission (stroke severity indicators inability to walk, arm weakness, speech impairment on admission and incontinence within 72 hours), past history of stroke/transient ischemic attack, and hypertension 


\begin{tabular}{|c|c|c|c|c|c|c|}
\hline \multicolumn{7}{|c|}{ Stroke Unit Care } \\
\hline Outcomes & \multicolumn{2}{|r|}{$\begin{array}{l}\text { Yes } \\
\mathrm{N}=404 \\
\mathrm{n}(\%)\end{array}$} & \multicolumn{2}{|c|}{$\begin{array}{c}\text { No } \\
\mathrm{N}=289 \\
\mathrm{n}(\%)\end{array}$} & $\begin{array}{r}\text { Adjusted } \\
\mathrm{OR}^{\circ}\end{array}$ & $95 \% \mathrm{CI}$ \\
\hline \multicolumn{7}{|l|}{ Complications } \\
\hline Aspiration pneumonia & 55 & 13.6 & 39 & 13.5 & 1.11 & $0.62,2.00$ \\
\hline Fall & 35 & 8.7 & 19 & 6.6 & 1.71 & $0.70,4.13$ \\
\hline Fever & 65 & 16.1 & 38 & 14.5 & 1.35 & $0.76,2.40$ \\
\hline Hemorrhagic transformation & 19 & 4.7 & 4 & 1.4 & 5.06 & $1.06,24.10$ \\
\hline Atrial fibrillation - new onset & 20 & 5.0 & 9 & 3.1 & 1.25 & $0.50,3.11$ \\
\hline New stroke & 6 & 1.50 & 13 & 5.0 & 0.57 & $0.15,2.89$ \\
\hline Stroke progression & 32 & 7.9 & 51 & 17.7 & 0.36 & $0.19,0.67$ \\
\hline Urinary tract infection & 42 & 10.4 & 31 & 10.7 & 1.38 & $0.75,2.55$ \\
\hline Seizure & 18 & 4.5 & 7 & 2.4 & 1.80 & $0.63,5.13$ \\
\hline \multicolumn{7}{|l|}{ Death and independence at discharge } \\
\hline Primary aim was palliative care & 55 & 13.6 & 97 & 33.6 & 0.31 & $0.18,0.54$ \\
\hline Died in hospital & 68 & 16.8 & 88 & 30.5 & 0.55 & $0.34,0.89$ \\
\hline Independent on discharge (mRS $0-2)^{*}$ & 41 & 12.2 & 12 & 6.0 & 1.74 & $0.51,5.91$ \\
\hline \multicolumn{7}{|l|}{ Hospital and discharge outcomes } \\
\hline Discharged to residential care (new admission) & 35 & 10.4 & 21 & 10.4 & 1.15 & $0.51,2.58$ \\
\hline Discharged to inpatient rehabilitation & 78 & 23.2 & 23 & 11.4 & 2.17 & $1.03,4.56$ \\
\hline \multirow[t]{2}{*}{ Received no ongoing rehabilitation ${ }^{\wedge}$} & 190 & 82.6 & 147 & 93.6 & 0.24 & $0.08,0.72$ \\
\hline & & & & & Co-efficient ${ }^{\circ}$ & $95 \% \mathrm{CI}$ \\
\hline Length of stay median ${ }^{*}$ (median Q1, Q3) & 6 & $3,11^{\dagger}$ & 6 & 2,10 & 1.0 & $-0.47,2.47$ \\
\hline
\end{tabular}

